\title{
Environmental protection preferences under strain: an analysis of the impact of changing individual perceptions of economic and financial conditions on environmental public opinion during economic crisis
}

John Kenny, University of Oxford

\begin{abstract}
This paper uses panel survey data from 2002-2008 - covering a period of economic prosperity and intense economic difficulties - to analyse the impact of changing levels of economic and financial security from the 2008 economic crisis on individuals' environmental protection preferences. Declining economic conditions in the aftermath of the crisis have been thought to produce lower levels of support for environmental protection and previous literature has predominantly supported this claim. Due to the availability of data, most analysis undertaken to date has focused on aggregate changes using repeated cross-sectional data and various economic indicators. Research looking at individual-level change and how individuals' perceptions of changing economic conditions may affect their prioritisation on environmental protection has however been lacking. This paper finds that neither changing economic perceptions nor changing household financial circumstances can account for the decline in environmental protection prioritisation witnessed in the aftermath of the great recession.
\end{abstract}

Keywords: environmental public opinion; economic recession; panel-data analysis; New Zealand

The Version of Record of this manuscript has been published and is available in the Journal of Elections, Public Opinion and Parties at the following link:

https://doi.org/10.1080/17457289.2017.1395884

\section{Introduction:}

A sudden and substantial increase in climate change scepticism and drop in concern for environmental issues was witnessed across the western world in the final years of the 2000s (Nielson 2009). As this phenomenon coincided with the occurrence of the global financial and economic crisis, it has been suggested that declining economic conditions may have been at least partly responsible. This is steeped in the idea that individuals have a finite pool of worry and thus will value the environment less during dire economic conditions while they concentrate on immediate material considerations. 
However, more empirical evidence is required to be able to ascertain the mechanism through which the recession may have affected environmental support. Is it that when individuals perceive the state of the economy to be worsening that they reflect on the challenges it poses for their country's prosperity, its ability to upkeep frontline services and the negative effects for the general health of the country's finances, and so may be likely to consider the restoration of a healthy economy as paramount even if such a recovery would involve environmental damage? Or is it because deep recession negatively affects individuals' personal financial wellbeing? This could be through factors such as lower incomes or losing one's job which may then result in people struggling to keep up with their household expenses. In such a scenario, environmental degradation may be seen as a price worth paying in the short-term if it restores their ability to maintain a decent standard of living. Neither of these two scenarios are mutually exclusive and it may be a combination of both. There is also the possibility that the co-occurrence of the great recession and the decline in environmental concern is spurious. As well as the recession, other potential factors for this lowering of support include issue fatigue (Gough 2011, 29), declining attention to the issue in the media or media coverage of climate skeptic arguments (Boykoff and Mansfield 2008; Leiserowitz et al. 2013), and increasing partisan polarisation on the issue in certain contexts (McCright, Dunlap, and Marquart-Pyatt 2015; Dunlap, McCright, and Yarosh 2016) during this period.

Many studies have analysed this puzzle during this timeframe with the vast majority finding, using various measures and indicators, that more severe declines in economic conditions are associated with greater declines in environmental prioritisation and that the crisis can be held responsible for declining environmental concern in general (Kahn and Kotchen 2011; Scruggs and Benegal 2012; Shum 2012; Conroy and Emerson 2014). Not only does the literature suggest that the recession affected prioritisation of environmental issues, but also that it could have changed people's belief in the anthropogenic cause of climate change and increased their uncertainty of the damage being done (Scruggs and Benegal 2012; 
Hennes et al. 2016). While some research challenges such claims (Kachi, Bernauer, and Gampfer 2015) or suggests that the effect of recessions on environmental concern has weakened over time (Harring, Jagers, and Martinsson 2011), the evidence so far overwhelmingly points to worsening economic conditions resulting from the crisis having an adverse effect on environmental attitudes.

Despite the prevalence of this viewpoint in the literature, most of this research has relied on repeated cross-sectional data to examine the research question which is problematic. While repeated cross-sectional analysis allows for an examination of the role of changing economic circumstances on environmental protection preferences at the aggregate level, it comes with deficiencies for the establishment of causality. A fundamental requirement for establishing causality is that any association between variables must not be the result of another omitted variable (Frees 2004, 11). While this is often a shortcoming of crosssectional data, panel data is better equipped to deal with omitted variable bias as by tracking the same individuals over time, one can essentially 'use each individual as his or her own control' (Allison 2009, 2). This approach also enables one to gain a more insightful understanding of the effects of changing individual characteristics on the variable of interest as opposed to the aggregate understanding one gets through analysing repeated crosssectional data (Frees 2004, 7/8). However, while becoming more frequent, the dissemination of panel data studies that contain questions about environmental protection preferences has not been very common. This is especially the case in obtaining such panel data that covers not only both before and after the onset of the economic crisis but where the post-crisis collection has occurred before the 2009 climategate scandal.

I have identified such a dataset in the New Zealand Election Study (2008) (NZES). This has a panel of respondents beginning in 2002 and continuing through 2005 to late 2008 . The dataset contains a question on individuals' environmental protection priorities as well as both their perceptions of the national economy and their own household financial conditions. 
Analysing this data allows for a unique opportunity to examine the effect of the crisis on individuals' environmental protection priorities.

\section{Theory:}

Changing perceptions of the general health of the economy and one's own financial situation are expected to affect individuals' environmental protection preferences for a number of reasons. There is a long-standing view in much of the literature that individuals in advanced industrial societies will have a higher likelihood of developing a deep concern for the environment when they are financially secure (Dunlap, Grieneeks, and Rokeach 1983). This is based somewhat on Maslow's (1970) hierarchy of needs which proposes that individuals need to fulfil their lower-order needs - including financial security - before turning attention towards higher-order needs. Inglehart builds on this in his postmaterialist thesis where though he proposes that postmaterialist value orientations - of which he considers environmental dispositions to form part of - are formed prior to adulthood and remain relatively fixed thereafter, he also notes that period effects from events such as economic recessions can produce short-term, downward fluctuations in such values due to the renewed prioritisation of material needs (Inglehart 1983). While it is arguable that protecting the environment so that it is clean, safe and secure should be regarded as a basic need, many individuals perceive environmental degradation to be a problem distant in both time and space as it often occurs slowly and so do not rank it as an immediate priority (Kollmuss and Agyeman 2002). They may also have difficulty in psychologically accepting the seriousness of environmental problems as by doing so it may compel them to accept solutions to ameliorate these that may challenge their own assumptions on economic prosperity, material needs and their standard of living (Nordhaus and Shellenberger 2009). This can be regarded as an egocentric explanation for why individuals may deprioritise environmental protection during periods of economic difficulties. 
The issue can also be looked at through the lens of diminishing marginal returns. In good times in prosperous countries wealth in itself may be valued less as there is plenty of it and so there may be a greater willingness to use it to fulfil other societal goals, whereas in times of (perceived) economic scarcity citizens may value it more relative to other noneconomic goods and thus may be less supportive of liberal policy aims that would require redistribution (Durr 1993, 159). This thus can capture more of a socio-centric viewpoint for why environmental protection prioritisation may decline when the economy is worsening, and is a reason drawn upon by Elliot, Regens and Seldon (1995) for their finding that as real incomes increase individuals are more willing support increased public spending on environmental protection, and vice-versa when real incomes decrease. The individual-level and societal-level explanations are not necessarily mutually exclusive either, with Conroy and Emerson (2014) finding that individuals with higher incomes tend to see less of an effect of poor macro-economic conditions on their concern for the environment.

The testing of hypotheses examining the connection between worsening economic conditions and public opinion on environmental protection following the 2008 recession has been undertaken in various studies, however as mentioned they have been limited by their reliance on repeated cross-sectional data. By using panel data from the NZES, I will make a novel contribution to this literature. Firstly, the panel element enables me to overcome the limitations in establishing a causal relationship that accompanies the cross-sectional analysis that has been the most prominent thus far. Secondly, the timings of the survey waves occurring during a period of economic prosperity and while the worst effects of the recession were still being felt - should provide a desirably large amount of variation in economic conditions to examine the effect of economic perceptions on environmental protection viewpoints. Thirdly, it allows me to examine the effect of individuals' perceived changes in both their own financial circumstances and the national economy on their environmental protection priorities over the use of objective economic indicators which, as Kachi, Bernauer 
and Gampfer (2015) note, have been dominant in much of the research undertaken thus far. The issue with objective indicators is that they may poorly proxy for individuals' actual economic sensitivities' (Gabel and Whitten 1997, 82). This is because one cannot make use of the fact that even in 'objectively' good or bad economic times, there is heterogeneity in how individuals perceive the economy to be performing as economic perceptions are influenced by a number of different factors including partisanship (Evans and Andersen 2006), cues from one's local area (Reeves and Gimpel 2012) and the media (Duch, Palmer, and Anderson 2000). Individuals need to perceive economic conditions in order for them to effect their political attitudes, but if the measure one is using is an objective measure that does not capture an individuals' perceived reality, then one may have too much noise and thus 'subjective perceptions of economic conditions are the best indicators for examining how economic conditions relate to political attitudes' (Gabel and Whitten 1997, 84). Through the questions contained in the NZES, in combination with its panel data structure, I will be able to capture such variations in individuals' perceptions and test the following hypotheses:

H1: As individuals feel less positive about the state of the national economy, their level of support for prioritising environmental protection will decrease.

H2: As individuals experience a negative change in their household financial situation, their level of support for prioritising environmental protection will decrease.

\section{Data:}

I use panel data from the 2002, 2005 and 2008 NZES in this paper. The panel data wave that began in 2002 was issued by mail following the general election and has a total of 1,741 respondents ${ }^{1}$. In total, 664 individuals remained in the panel for all three waves representing a

\footnotetext{
${ }^{1}$ I have excluded individuals that were sampled by telephone following the postal survey as they were not asked the environmental protection question.
} 
retention rate of $36 \% .623$ of these provided responses in all three waves to the environmental protection question that serves as the dependent variable in this analysis.

The timing of these waves makes them particularly useful for tackling this paper's research question given the changing economic conditions between them. From the period of 1999 to 2007, New Zealand experienced an unprecedented and sustained level of economic prosperity. The 1999-2002 parliamentary period saw New Zealand's best export figures for decades (Grafton 2003, 111) and strong economic conditions continued going into the 2005 general election where the country had the lowest unemployment rate in the OECD at $3.7 \%$, an annual growth rate over the previous years of over $4 \%$ and a budget surplus of NZ\$7 billion (Knox 2005). Thus in both 2002 and 2005 individuals were living in an era of unusually high levels of economic security.

By 2008 however, conditions had declined dramatically. The country entered into recession in the first quarter, with consecutive summer droughts in 2007 and 2008 adversely affecting the key dairy industry and high prices for food and fuel greatly reducing consumer consumption. New Zealand's economy suffered further from the ripple effect of the collapse of Lehman Brothers and the advent of the global financial crisis, with reduced business and consumer confidence, restricted access to international capital and an overall contracting of economic activity (The Treasury 2010,11). The severity of the crisis became particularly apparent just as campaigning for the general election began (Edwards 2009, 1057) and it was in such a setting of extreme economic instability that the 2008 data was collected ${ }^{2}$. Thus, this panel should provide a desirable amount of variation in perceptions of economic and household financial security to allow me to investigate the impact of such changes on individuals' environmental protection preferences.

\footnotetext{
${ }^{2}$ It should also be noted that, though the environment was a salient issue in political discourse in New Zealand at this time, it was also an issue in which there was 'increasingly ... consensus' (Edwards 2009, 1058) among the political parties and so it did not play a defining role by itself in the election.
} 
One of the first questions to ask is whether those that dropped out of the panel in 2002 are characteristically different to those that remained. To do this, I carry out a logistic regression in which a range of factors are regressed upon remaining in the sample until 2008. This displays two key ways in which the retained sample differs from those that dropped out. Firstly, those who rented or lived rent free/boarded in 2002 are less likely to have remained than those who own their homes outright or have a mortgage. As the method of distribution is a postal survey, this should be expected - as the former categories contain individuals who may be living in temporary accommodation and so the sampling design is more likely to lose those who move in between. Previous studies have also found that non-home owners are more likely than home owners to be lost in subsequent panel waves (Zabel 1998). Secondly, age is significantly related to attrition, with the 18-25 group being the least likely to remain. This also corresponds with other studies that find that young adults are the most likely to drop out, but this panel does not suffer from an additional common problem of high attrition among the elderly (Ribisl et al. 1996). While these are the two biggest issues, additionally those who respond with the highest environmental response on an environmental protection versus safeguarding incomes question ${ }^{3}$ are more likely to have dropped-out of the panel. This is likely to be related to age attrition as younger individuals tend to have stronger support for the environment (Van Liere and Dunlap 1980). Finally, on media consumption, readers of the Dominion newspaper are more likely to remain in the sample than readers of the New Zealand Herald.

To deal with this, I created inverse probability weights in which one's housing situation, age group, environmental protection score and newspaper readership were used as covariates being the variables that are significantly related to attrition. Weighting the data with these inverse probability weights, post-stratification weights were then calculated using reference data from Statistics New Zealand (2016) - that correct the 2002 sample to

\footnotetext{
${ }^{3}$ This question will be used as the dependent variable in the analysis and is detailed below.
} 
match the New Zealand population on age and gender ${ }^{4}$. The post-stratification weights, the inverse probability weights and the design weights included in the survey that account for the Maori oversample were then multiplied together to produce the final weight. Thus, this weight should ensure that the analysis accounts for differential attrition, the population's basic demographic characteristics and the survey's sampling design.

\section{Variables:}

The dependent variable asks respondents to place themselves on a seven-point scale ranging from 'That we should safeguard our income levels before we seek to protect the environment' (recoded as 1) to 'That we should concentrate more on protecting the environment, even if it leads to considerably lower incomes' (recoded as 7). This is a strong measure as it captures prioritisation of environmental protection in the presence of scarce economic resources (Diekmann and Franzen 1999). The mid-point response category can be interpreted either as respondents giving an equal weighting to both options or that they cannot decide which they would prefer to see prioritised. As the question makes it clear that one is answering in a scenario where both options cannot be pursued at once, then this ' 4 ' response can be deemed as functionally equivalent to don't know and I have thus relabelled these as 4. Unfortunately, there was a labelling mistake in the questionnaires in both 2002 and 2005 that may introduce extra error but, while not ideal, there are very good reasons to believe that the questions do capture what they were meaning to with reliable indicators of environmental concern (educational attainment, membership of an environmental organisation and one's left-right placement on the political spectrum) correlating as one would expect them to with the question responses. This issue is detailed in appendix A.

There are two independent variables that will be used as measures of individuals' feelings of economic and financial security. The first asks 'How do you think the general economic situation in the country now compares with a year ago?' while the second asks

\footnotetext{
${ }^{4}$ While the survey itself is of voters rather than the population, as voter registration is compulsory in New Zealand this justifies using gender and age data from the population to weight the data.
} 
'How does the financial situation of your household now compare with what it was 12 months ago?' with the answers ranging on a five-point scale from 'a lot better' (recoded as 5) to 'a lot worse' (recoded as 1) in addition to a 'don't know' option. It is expected that as individuals perceive the state of the national economy and their household financial situation to be worsening, the lower their prioritisations will be for prioritising environmental protection.

In addition, I include a number of control variables. For the model using fixed effects, there will be three. I use a measure of partisanship through a question that asks which party the respondent voted for on the party list ballot and, if one did not vote, which party they would have voted for had they voted due to partisanship being closely related to environmental protection preferences (Ivanova and Tranter 2008; McCright and Dunlap 2011). The categories used are Labour, National, Greens, New Zealand First, other party and no party. Household income was measured using a question asking respondents to pick the income bracket their household income fell under, with the exact amounts changing in each of the waves of survey to account for national increases in incomes. As not many individuals change income brackets from wave to wave, it is not expected that this measurement provided in the survey will have much of an effect. I have also included a variable asking whether the respondent is in receipt of unemployment benefits. For the models not using fixed effects, I additional include the following controls. Education will be added using a question that asks for one's highest formal education attainment coded under categories of primary or less, secondary education, nondegree professional trade or technical tertiary qualification, incomplete university degree or university degree. Gender will be controlled for, as well as newspaper readership as an indicator of media consumption. Newspaper 
readership was not asked in 2008, however given the high level of stability between 2002 and 2005 the newspaper that individuals read in 2005 will used as a proxy ${ }^{5}$.

\section{Methods:}

There will be three steps taken to analyse the data. Firstly, descriptive statistics will be presented to examine both the aggregate and individual level change in environmental attitudes and retrospective economic/household financial perceptions and the relationship between them. Secondly, to test whether the magnitude of change in individuals' economic and household finance perceptions affects their prioritisation of environmental protection, a first differences approach will be taken. While the first differences approach will give an initial indication of the relationship, it is not sufficient due to the dependent variable being of an ordinal nature as the first differences approach assumes that the distance between each category is of an equal quantifiable value which may lead to heteroskedastic errors. Hence, a more robust method that will be the third step in the analysis is to carry out an ordered fixed effects logit model on the data.

This will be done using Baetschmann, Staub and Winkelmann's (2015) blow-up and cluster (BUC) estimator. While there is as yet no consensus for the best approach to take to carry out fixed effects ordered logit models and standard statistical software packages do not have built-in commands for these (Longhi and Nandi 2015, 208/209), there are a number of desirable reasons for choosing this particular estimator. The estimator works by replacing each observation in a sample with an ordinal dependent variable of $\mathrm{k}$ categories by $\mathrm{k}-1$ copies of itself, dichotomising each of these copies at a different cut-off point and getting the estimates by applying conditional maximum likelihood estimation on the full sample where the standard errors are clustered at the individual level (Baetschmann, Staub, and Winkelmann 2015, 690). Running Monte Carlo simulations on a number of alternative methods, Riedl and Geishecker (2014) find the BUC estimator to provide the most efficient,

\footnotetext{
${ }^{5}$ Additionally, where individuals did not respond to the newspaper question in 2005, their answers from 2002 have been used.
} 
consistent and unbiased estimator irrespective of the sample size for analysing ordinal dependent variables using fixed effects. Additionally, Dickerson, Hole and Munford (2011) find the estimator to be preferred when there are some response categories with very low numbers of responses, as is the case for the environmental question in the NZES.

\section{Results:}

To begin with, I present descriptive statistics. Table 1 displays the aggregate change in responses to the environmental protection versus income question over the course of the panel. The change in prioritisation of environmental protection is consistent with theoretical expectations. Under conditions of sustained economic growth between 2002 and 2005, there was an increase in the number of people who would prioritise environmental protection, rising from $38 \%$ who would lean this way in 2002 to $49 \%$ in 2005 . In 2008 , during the period of economic strife, one witnesses a clear decline in prioritisation of environmental protection with a plurality of individuals who would lean towards the prioritisation of incomes instead. At $45 \%$ of respondents opting to prioritise safeguarding incomes, this is 2.5 times the level of such responses in 2005. This is the first time since the question was asked in the 1990 study (New Zealand Election Study 1998) that more individuals would prioritise safeguarding incomes over environmental protection which shows a real shift in public opinion.

\section{[INSERT TABLE 1 HERE]}

Table 2 displays how aggregate responses to the economic and household financial perception questions have varied in the panel over the 2002-2008 period. Between 2002 and 2005 , the overall change in individuals' retrospective economic evaluations and their view of their own household financial situation remained relatively static, with pluralities in both cases regarding the situation to be unchanged from twelve months beforehand. This is to be expected given that both periods were during similar periods of economic prosperity. Yet the changes in 2008 clearly demonstrate an increase in feelings of economic and financial insecurity. Only $3 \%$ of people thought that the economy had improved while almost $90 \%$ 
believed the state of the economy had gotten worse. This is evenly split between those who consider the economy to have gotten a little worse and a lot worse - the latter of which has a slightly lower proportion. People's opinions on how their household finances have changed show a similar, though less severe, pattern. Thus, the shifts in responses to these questions over the course of the panel are in line with what one would expect.

\section{[INSERT TABLE 2 HERE]}

The previous tables demonstrate the aggregate changes that have occurred in individuals' environmental protection prioritisation, their retrospective economic perceptions and their household finances. To ascertain whether these occurrences are related, I make use of the panel structure of the data to look at whether the individuals who become more insecure are also those whose environmental protection priorities lessened. Table 3 shows the percentage of individuals whose response to the environmental protection versus income question increased, stayed the same or decreased according to whether their economic evaluations and their reported household finances worsened or stayed the same/got better in 2008 compared to their previous response in 2005 . The focus is on the change in the 2008 wave as that is where the aggregate responses suggest change occurred. There are two contrasting outcomes. Individuals whose economic evaluations worsened have a higher number of responses - by 3 percentage points - of individuals whose environmental protection score decreased and a lower number of responses - by 9 percentage points - of individuals whose environmental protection score increased. In looking at the figures under the household finances column however, one sees that there is virtually no difference between the group of individuals whose situation did and did not worsen. This tabulation only takes into account a binary distinction between whether one's viewpoint changed or not rather than the magnitude of such changes, and thus this will now be examined.

[INSERT TABLE 3 HERE] 
Table 4 displays the results of regressions that utilise a first differences approach to examine the hypotheses whereby the environmental protection question and both the economic and household finance evaluation questions are treated as continuous responses and the changes in these - as well as a number of undifferenced controls - are then regressed on the changes in the environmental protection questions. While it was not expected to find an effect of changing household financial perceptions on environmental protection prioritisation based on the crosstabulations in table 3 - which is confirmed - what is clear is that neither do changing economic evaluations have any significant relationship with the dependent variable. While the change in retrospective economic evaluations are negatively associated with the change in environmental protection preferences as hypothesised and this association is stronger in 2008 than 2005, this association is not statistically significant.

\section{[INSERT TABLE 4 HERE]}

The results from ordinal fixed effects models using the BUC estimator to further investigate this are displayed in Table $5^{6}$. In model 1 , I regress the environmental protection dependent variable on retrospective economic evaluations, perceived changes in one's household financial situation, income, partisanship and being in receipt of unemployment benefit. This model shows a lack of a statistically significant relationship between the explanatory variables of interest and prioritisation of envirosnmental protection ${ }^{7}$. Keeping every other variable at their mean value, the marginal effect of macro-economic perceptions varies from 0.32 [95\% CI: 0.11-0.53] to 0.26 [95\% CI: $0.01-0.51]$ and for household financial circumstances the marginal effect goes from 0.26 [95\% CI: $0.08-0.43$ ] to 0.34 [95\% CI: 0.06-

\footnotetext{
${ }^{6}$ If respondents provided a don't know response or no response at all to either the retrospective economic evaluation or household financial situation question in any of the three waves, they were dropped for the analysis for reason described above. A further $13 \%$ of this reduced sample were omitted as the BUC estimator drops observations for which the value of the dependent variable did not change throughout the panel, hence the final number of respondents of 484 .

${ }^{7}$ The coefficient for the change in retrospective evaluations variable is -0.07 [95\% CI: $-0.29-0.15$ ] while the coefficient for the change in one's household financial situation variable is 0.11 [95\% CI: $-0.10-0.31$ ].
} 
0.63] respectively as perceptions go from much worse to much better. Though not reaching statistical significance, given how few people receive unemployment benefit in the sample, it is notable that the being in receipt of unemployment benefit coefficient is negatively associated with the environmental variable with a relatively low p-value of 0.13 . Lastly, the year dummy variables confirm an increase in individuals' environmental protection priorities from 2002 to 2005 and a subsequent decrease in 2008.

It could be that changes in prioritisation of environmental protection may be related to concurrently feeling that both the national economy and one's individual financial circumstances have both got worse. To test this, in model 2 I add an interaction between these two variables. This interaction term is again statically insignificant. A final test is to see if the effect of changing economic/household financial perceptions on environmental prioritisation differs depending on one's level of income. To do this, in model 3, I instead add interactions between these two variables and one's income bracket. The coefficients of these interaction terms demonstrate no clear pattern though and are statistically insignificant.

While it appears that on the whole individuals' dispositions towards environmental protection dropped at the same time as aggregate economic perceptions and household finance conditions declined, these results show that the relationship between these is spurious as individual change in economic perceptions and household finances does not correspond with individual change in prioritisation of environmental protection. Thus, I reject both H1 and $\mathrm{H} 2$.

\section{[INSERT TABLE 5 HERE]}

To check the robustness of these results, I have carried out three further tests on the models in Table 5. Firstly, I ran the models without using the survey weights. Secondly, I ran the models using a variable capturing how respondents expect the economy to change in the next 12 months instead of their retrospective economic evaluations. Thirdly, I condensed the dependent variable into three categories (income leaning, neither income nor environment 
leaning or environment leaning) and carried out linear fixed effect models with clustered standard errors. None of these tests alter the main findings from any of the models.

\section{Conclusion:}

This paper set out to examine whether changes in individuals' feelings of economic and financial security resulting from the global economic and financial crisis of 2008 impacted upon their prioritisation of environmental protection. While the occurrence of the crisis provides the ideal variation in economic conditions under which to examine this, previous studies that have made use of these changes to analyse their effect on environmental public opinion have mostly concentrated on aggregate rather than individual change. Through using NZES panel data that covers a period of economic prosperity preceding the crisis and a period of economic anxiety in the midst of the crisis, this paper was able to focus on change at the individual level.

Despite the presence of dramatic changes in economic conditions during the course of this panel - changes that the data shows are perceived by the public - there is no indication that increasing feelings of economic and financial insecurity affect prioritisation of environmental protection. While at the aggregate level the measures of increasing economic and financial insecurity correspond with a lower prioritisation of environmental protection, at the individual level there is no connection between deteriorating household finances and environmental protection preferences. The small correlation between deteriorating economic perceptions and environmental protection preferences is not statistically significant and cannot account for the magnitude of the decline witnessed.

Even though the correlation at the aggregate level appears to be coincidental, this is not to say that one can rule out the recession from playing a role in the lessening of the prioritisation of the environmental protection. If it did however, it is likely to have been through other mechanisms such as crowding out environmental issues from public discourse due to the attention given towards economic issues in a scenario where there is limited issue 
space (Downs 1972; Brulle, Carmichael, and Jenkins 2012, 185). One may also look to other notable events that occurred between 2005 and 2008 that may provide alternative explanations. The highly-publicised 2006 documentary An Inconvenient Truth warned of the severe dangers facing the planet from global warming and urged for urgent action to be taken. This could have provoked a system justification response among sections of the public who could have become less likely to prioritise economic and lifestyle changes to protect the environment when presented with an apocalyptic message in order to fulfil a psychological need to maintain a positive view of the existing social order (Nordhaus and Shellenberger 2009). The subsequent release of the controversial climate change denial documentary The Great Global Warming Swindle - which received large amounts of public attention and was broadcasted in an edited form on New Zealand television - could also have contributed through sowing the seeds of doubt on whether global warming/climate change is anthropogenically caused which may have affected support for mitigation measures (Mellor $2009,135)$. The testing of these alternative explanations is however beyond the scope of this current study.

Though the preponderance of prior literature suggests that increasing feelings of economic and financial insecurity from the great recession were responsible for declining public prioritisation of environmental issues, this article makes an important contribution by demonstrating that such a straightforward relationship may not exist. As the first piece of research to examine the issue using individual panel data from either side of the onset of the crisis, it is a key finding that changing feelings of economic and financial security on environmental protection prioritisation at the aggregate level is not matched at the individual level.

\section{References:}

Allison, Paul D. 2009. Fixed Effects Regression Models. London: Sage Publications.

Baetschmann, Gregori, Kevin E. Staub, and Rainer Winkelmann. 2015. "Consistent 
Estimation of the Fixed Effects Ordered Logit Model." Journal of the Royal Statistical Society. Series A: Statistics in Society 178 (3): 685-703.

Boykoff, Maxwell T, and Maria Mansfield. 2008. “Ye Olde Hot Aire': Reporting on Human Contributions to Climate Change in the UK Tabloid Press.” Environmental Research Letters 3 (2): 1-8.

Brulle, Robert J., Jason Carmichael, and J. Craig Jenkins. 2012. "Shifting Public Opinion on Climate Change: An Empirical Assessment of Factors Influencing Concern over Climate Change in the U.S., 2002-2010." Climatic Change 114 (2): 169-88.

Conroy, Stephen J., and Tisha L.N. Emerson. 2014. "A Tale of Trade-Offs: The Impact of Macro-Economic Factors on Environmental Concern.” Journal of Environmental Management 145: 88-93.

Diamantopoulos, Adamantios, Bodo B. Schlegelmilch, Rudolf R. Sinkovics, and Greg M. Bohlen. 2003. “Can Socio-Demographics Still Play a Role in Profiling Green Consumers? A Review of the Evidence and an Empirical Investigation.” Journal of Business Research 56 (6): 465-80.

Dickerson, Andy, Arne Risa Hole, and Luke Munford. 2011. "A Review of Estimators for the Fixed Effects Ordered Logit Model.” In 2011 UK Stata Users Group Meeting. London. http://www.stata.com/meeting/uk11/abstracts/UK11_Hole.pdf.

Diekmann, Andreas, and Axel Franzen. 1999. "The Wealth of Nations and Environmental Concern.” Environment and Behaviour 30 (4): 540-49.

Downs, Anthony. 1972. "Up and down with Ecology: The 'Issue-Attention Cycle."” The Politics of American Economic Policy Making 28: 38-50.

Duch, Raymond M., Harvey D. Palmer, and Christopher J. Anderson. 2000. "Heterogeneity in Perceptions of National Economic Conditions.” American Journal of Political 
Science 44 (4): 635-52.

Dunlap, Riley E., Aaron M McCright, and Jerrod H. Yarosh. 2016. “The Political Divide on Climate Change: Partisan Polarization Widens in the U.S.” Environment: Science and Policy for Sustainable Development 58 (5): 4-23.

Dunlap, Riley E, J. Keith Grieneeks, and Milton Rokeach. 1983. "Human Values and ProEnvironmental Behaviour." In Energy and Material Resources: Attitudes, Values and Public Policy, edited by W. David Conn, 145-68. Bouldor, Colorado: Westview Press.

Durr, Robert H. 1993. "What Moves Policy Sentiment?.” American Political Science Review 87 (1): $158-70$.

Edwards, Bryce. 2009. "New Zealand.” European Journal of Political Research2 48 (7-8): $1052-66$.

Elliott, E, James L. Regens, and Barry J. Seldon. 1995. "Exploring Variation in Public Support for Environmental Protection.” Social Science Quarterly 76 (1): 41-52.

Evans, Geoffrey, and Robert Andersen. 2006. "The Political Conditioning of Economic Perceptions.” Journal of Politics 68 (1): 194-207.

Frees, Edward W. 2004. Longitudinal and Panel Data: Analysis and Applications in the Social Sciences. Cambridge: Cambridge University Press.

Gabel, Matthew, and Guy D. Whitten. 1997. "Economic Conditions, Economic Perceptions, and Public Support for European Integration.” Political Behavior 19 (1): 81-96.

Gough, Ian. 2011. Climate Change and Public Policy Futures. London: British Academy.

Grafton, Tim. 2003. "National's Campaign.” In New Zealand Votes: The General Election of 2002, edited by Jonathan Boston, Stephen Church, Stephen Levine, Elizabeth NcLeay, and Nighel S. Roberts, 111-17. Wellington: Victoria University Press. 
Harring, N., S. C. Jagers, and J. Martinsson. 2011. "Explaining Ups and Downs in the Public's Environmental Concern in Sweden: The Effects of Ecological Modernization, the Economy, and the Media." Organization \& Environment 24 (4): 388-403.

Hennes, Erin P., Benjamin C. Ruisch, Irina Feygina, Christopher A. Monteiro, and John T. Jost. 2016. "Motivated Recall in the Service of the Economic System: The Case of Anthropogenic Climate Change.” Journal of Experimental Psychology: General 145 (6): $755-71$.

Inglehart, Ronald. 1983. "The Persistence of Materialist and Post-Materialist Value Orientations: Comments on Van Deth's Analysis.” European Journal of Political Research 11 (1): 81-91.

Ivanova, Galina, and Bruce Tranter. 2008. "Paying for Environmental Protection in a CrossNational Perspective.” Australian Journal of Political Science 43 (2). Routledge: 16988.

Kachi, Aya, Thomas Bernauer, and Robert Gampfer. 2015. "Climate Policy in Hard Times: Are the Pessimists Right?” Ecological Economics 114: 227-41.

Kahn, Matthew E., and Matthew J. Kotchen. 2011. "Business Cycle Effects on Concern About Climate Change: The Chilling Effect of Recession." Climate Change Economics 2 (3): $257-73$.

Knox, Angie. 2005. "NZ Election Goes to the Wire.” BBC News, September 13. http://news.bbc.co.uk/1/hi/world/asia-pacific/4240444.stm.

Kollmuss, Anja, and Julian Agyeman. 2002. "Mind the Gap: Why Do People Behave Environmentally and What Are the Barriers to Pro-Environmental Behaviour." Environmental Education Research 8 (3): 239-60.

Leiserowitz, Anthony, Edward Maibach, Connie Roser-Renouf, Nicholas Smith, and Erica 
Dawson. 2013. "Climategate, Public Opinion, and the Loss of Trust.” American Behavioral Scientist 57 (6): 818-37.

Longhi, Simonetta, and Alita Nandi. 2015. A Practical Guide to Using Panel Data. London: Sage Publications.

Maslow, Abraham H. 1970. Motivation and Personality. 2nd ed. New York: Harper and Row.

McCright, Aaron M, and Riley E Dunlap. 2011. "The Politicization Of Climate Change And Polarization In The American Public's Views Of Global Warming, 2001-2010.” Sociological Quarterly 52 (2): 155-94.

McCright, Aaron M, Riley E Dunlap, and Sandra T Marquart-Pyatt. 2015. "Political Ideology and Views about Climate Change in the European Union." Environmental Politics, 121.

Mellor, Felicity. 2009. “The Politics of Accuracy in Judging Global Warming Films.” Environmental Communication 3 (2): 134-50.

New Zealand Election Study. 1998. "Attitudes About the Environment, 1996." http://www.nzes.org/exec/show/env_1996.

—. 2008. "New Zealand Election Study Data: 2002-2008." http://www.nzes.org/exec/show/data.

Nielson. 2009. “Climate Change/Global Warming.” Nielson. http://www.nielsen.com/content/dam/corporate/us/en/newswire/uploads/2009/12/globalclimate-change-survey.pdf.

Nordhaus, Ted, and Michael Shellenberger. 2009. “Apocalypse Fatigue: Losing the Public on Climate Change." Yale Environment 360. www.e360.yale.edu/feature/apocalypse_fatigue_losing_the_public_on_climate_change/ 
Reeves, Andrew, and James G. Gimpel. 2012. “Ecologies of Unease: Geographic Context and National Economic Evaluations.” Political Behavior 34 (3): 507-34.

Ribisl, Kurt M., Maureen A. Walton, Carol T. Mowbray, Douglas A. Luke, William S. Davidson, and Bonnie J. Bootsmiller. 1996. "Minimizing Participant Attrition in Panel Studies through the Use of Effective Retention and Tracking Strategies: Review and Recommendations." Evaluation and Program Planning 19 (1): 1-25.

Riedl, Maximilian, and Ingo Geishecker. 2014. “Keep It Simple: Estimation Strategies for Ordered Response Models with Fixed Effects.” Journal of Applied Statistics 41 (11): $2358-74$.

Scruggs, Lyle, and Salil Benegal. 2012. "Declining Public Concern about Climate Change: Can We Blame the Great Recession?” Global Environmental Change 22 (2): 505-15.

Shum, Robert Y. 2012. "Effects of Economic Recession and Local Weather on Climate Change Attitudes.” Climate Policy 12 (1): 38-49.

Statistics New Zealand. 2016. “Estimated Resident Population by Age and Sex (1991+) (Annual-Dec).” Statistics New Zealand. http://www.stats.govt.nz/infoshare/ViewTable.aspx?pxID=653aa013-12da-4a68-877ea43437117c73.

The Treasury. 2010. "New Zealand Economic and Financial Overview 2010." The Treasury. http://www.treasury.govt.nz/economy/overview/2010.

Van Liere, Kent D., and Riley E. Dunlap. 1980. “The Social Bases of Environmental Concern: A Review of Hypotheses, Explanations and Empirical Evidence.” Public Opinion Quarterly 44 (2): 181-97.

Zabel, Jeffrey. 1998. "An Analysis of Attrition in the Panel Study of Income Dynamics and 
the Survey of Income and Program Participation with an Application to a Model of Labor Market Behavior.” Journal of Human Resources 33 (2): 479-506. 


\section{Appendix A: Note on Labelling Error}

In this note, I discuss a labelling error in the survey questionnaires in both 2002 and 2005 and the potential implications this may have for the study. In each wave from $2002-2008$, respondents were presented with the following statement and asked to tick a box that corresponds with their view:

ONE means that we should concentrate more on protecting the environment, even if it leads to considerably lower incomes, and SEVEN means that we should safeguard our income levels before we seek to protect the environment. Where would you place your view?

On a horizontal line from 1 to 7 , the correct label 'Protect environment even if it leads to lower incomes' was placed next to 1 on the left-hand side in all three waves but next to 7 on the right-hand side the label read 'Not protect environment even if it leads to lower incomes ${ }^{8}$, in both 2002 and 2005. By 2008, this had been corrected so that the right-hand side label read 'Safeguard incomes before protecting environment', thus matching the descriptions given in the question wording. This is problematic as one cannot know how much of any observed changes in responses to this question are because of the change of labels and how much are because of changes in environmental protection priorities. However, given that the question wording itself and the label for 1 remained the same, that the description in the question in each case specified that 7 meant to safeguard income levels before protecting the environment and that the intention of a conflict between environmental protection and income levels was clear, one would expect that respondents knew what was meant and that these surveys responses are comparable and thus can capture meaningful change in environmental priorities.

One way to test this is to analyse whether key factors that are known to correlate highly with strong environmental protection preferences are correlated in the expected direction with this question in both waves. The variables I have chosen to test this, which

\footnotetext{
${ }^{8}$ Italics added for emphasis.
} 
have been proven to relate strongly to environmental protection preferences (Van Liere and Dunlap 1980; Diamantopoulos et al. 2003), are educational attainment, membership of an environmental organisation and, as a measure of one's liberal orientation, one's left-right placement on the political spectrum ${ }^{9}$. In Table A1, one can see the results of two separate ordered logit regression models for the 2002 and 2005 waves respectively where the environmental protection question has been regressed on the above three variables. As in the analysis in the main body, for ease of interpretation the scale has been reversed so that 7 represents the highest support for prioritising environmental protection. The results are consistent with what one would expect if individuals interpreted the question as intended. Those with a university degree are more likely to have a higher environmental protection preference as identified by the question wording than those with lower educational attainment in both waves, with this difference being statistically significant compared to those with a secondary education in 2002 and those with a secondary or a nonprofessional trade/technical tertiary education in 2005. Likewise, members of environmental organisations are more likely to choose a higher environmental score as identified by the question wording. Finally, in 2002 and 2005 right-identifying individuals are statistically less likely than centreidentifying individuals to choose a higher category of environmental protection and in 2005 left-identifying induvial are statistically more likely to choose a higher category of environmental protection as identified by the question wording. Thus, while it is not ideal that this error was present, there are very good reasons to believe that the question was nonetheless able to accurately capture the change in individuals' environmental protection views over time.

\section{[INSERT TABLE A1 HERE]}

\footnotetext{
${ }^{9}$ Respondents are coded as left if they responded as 0-4, centre if they responded 5 and right if they responded 6-10, as well as having categories for 'don't know' and those who did not respond.
} 


\section{Environmental protection preferences under strain: an analysis of the impact of changing individual perceptions of economic and financial conditions on environmental public opinion during economic crisis}

Tables:

Table 1. Change in response to environmental protection v. income question 2002-2008 (\%)

\begin{tabular}{lccc}
\hline \multicolumn{1}{c}{ Environment v. Income } & 2002 & 2005 & 2008 \\
\hline 1. Safeguard Incomes & 4 & 2 & 7 \\
2. & 5 & 5 & 13 \\
3. & 13 & 11 & 25 \\
4. & 40 & 32 & 24 \\
5. & 21 & 26 & 16 \\
6. & 10 & 14 & 9 \\
7. Protect Environment & 7 & 9 & 6 \\
\% Column Total & 100 & 99 & 100 \\
\hline
\end{tabular}

Note: Figures rounded to the nearest whole number; $n=623$

Table 2. Change in retrospective economic evaluations and household finances 2002-2008 (\%)

\begin{tabular}{lccc|ccc}
\hline & \multicolumn{3}{c}{ Economic Evaluations } & \multicolumn{3}{c}{ Household Finances } \\
\hline Lot Better & 2002 & 2005 & 2008 & 2002 & 2005 & 2008 \\
Little Better & 2 & 2 & 0 & 3 & 5 & 6 \\
Same & 24 & 21 & 3 & 16 & 19 & 14 \\
Little Worse & 44 & 46 & 7 & 48 & 45 & 33 \\
Lot Worse & 20 & 22 & 46 & 25 & 24 & 33 \\
Don't Know & 3 & 1 & 42 & 4 & 5 & 13 \\
No Response & 6 & 7 & 1 & 2 & 2 & 0 \\
\% Column Total & 2 & 1 & 0 & 2 & 1 & 0 \\
\hline
\end{tabular}

Note: Figures rounded to the nearest whole number; $n=623$

Table 3. Individual changes in environmental protection response by their changes in their retrospective economic evaluations and household finances from 2005-2008 (\%)

Note: Individuals who responded 'don't know' or did not respond to the economic evaluation or household finance questions in either wave are not included in this table as one cannot ascertain how their views changed. 
Table 4. Regression of the change in environmental protection v. income question

Change in Retrospective Economic Evalutation

Change in Household Financial Situation

Gender (Male)

Newspaper (None/No Response)

Bay of Plenty Times

Daily News

Dominion

Hawkes Bay Today

Manawatu Evening Standard

New Zealand Herald

Otago Daily Times

The Press

Waikato Times

Other

Education (Completed University)

Incomplete Primary/None

Secondary

Non-Degree Professional Trade/Technical

Tertiary

Incomplete University

Partisanship (Labour)

National

Greens

New Zealand First

Other

None

Household Income Group (Bracket 1 - Lowest)

Bracket 2

Bracket 3

Bracket 4

Bracket 5 (Highest)

Receives Unemployment Benefit

Constant

$\mathrm{R}^{2}$

Number of Respondents

${ }^{* *} \mathrm{p} \leq 0.01 ; * \mathrm{p} \leq 0.05$; standard errors in parentheses

Note: Individuals who responded 'don't know' or did not respond to the economic evaluation or household finance questions in either wave are not included in this table as one cannot ascertain how their views changed. Don't know/no response responses for other questions are included in the model where available, though not displayed in the table.
$0.36(0.45)$

$-0.63(0.58)$

$-0.24(0.40)$

$-0.53(0.46)$

$-0.44(0.48)$

$-0.15(0.39)$

$-0.63(0.44)$

$-0.25(0.42)$

$-0.18(0.49)$

$-0.30(0.42)$

$0.26(0.44)$
$0.43(0.44)$

$-1.18(0.33)^{* *}$

$-0.10(0.19)$

$-0.22(0.21)$

$0.12(0.33)$

$-0.19(0.16)$

$0.02(0.31)$

$-0.30(0.32)$

$0.39(0.24)$

$-0.87(0.49)$

$0.22(0.33) \quad-0.06(0.30)$

$-0.02(0.36) \quad-0.38(0.40)$

$0.04(0.40) \quad-0.05(0.33)$

$0.21(0.33) \quad-0.25(0.31)$

$0.59(1.11) \quad-0.93(0.98)$

$-0.22(0.54) \quad-0.13(0.51)$

$\begin{array}{ll}0.10 & 0.09\end{array}$

563

577 
Table 5. Fixed effect ordered logistic regression of environmental protection $v$. safeguarding income question (2002-2008)

Retrospective Economic Evalutation

Household Financial Situation

Economic Evaluation*Household

Financial Situations

Income Group (Bracket 1)

Bracket 2

Bracket 3

Bracket 4

Bracked 5

Income Group (Bracket 1)

*Retrospective

Economic

Evaluations

Bracket 2

Bracket 3

Bracket 4

Bracked 5

Income Group (Bracket 1)

*Household Financial Situation

Bracket 2

Bracket 3

Bracket 4

Bracked 5

Partisanship (Labour)

National

Greens

New Zealand First

Other

None

Receives Unemployment Benefit

Year (2005)

2002

2008

Log Pseudoliklihood

Pseudo $\mathrm{R}^{2}$

Number of Respondents

\begin{tabular}{ccc}
$(1)$ & $(2)$ & $(3)$ \\
\hline$-0.07(0.11)$ & $0.24(0.23)$ & $-0.38(0.26)$ \\
$0.11(0.10)$ & $0.37(0.21)$ & $0.02(0.38)$
\end{tabular}

$-0.11(0.07)$

$\begin{array}{ccc}0.19(.40) & 0.18(0.41) & -0.93(1.20) \\ -0.56(0.53) & -0.58(0.52) & -1.96(1.24) \\ -0.15(0.46) & -0.18(0.46) & -0.27(1.15) \\ 0.13(0.52) & -0.14(0.51) & -1.43(1.14)\end{array}$

)

$* * \mathrm{p} \leq 0.01 ; * \mathrm{p} \leq 0.05 ;$ standard errors in parentheses

$\begin{array}{ccc}-0.52(0.28) & -0.51(0.28) & -0.54(0.28) \\ 1.41(0.58)^{*} & 1.43(0.59)^{*} & 1.39(0.56)^{*} \\ 0.02(0.37) & -0.00(0.37) & 0.01(0.34) \\ -0.14(0.34)^{*} & -0.15(0.34) & -0.18(0.32) \\ 0.80(0.82) & -0.81(0.82) & -0.74(0.68) \\ & & \\ -0.79(0.51) & -0.80(0.51) & -0.60(0.52)\end{array}$

$0.48(0.31)$

$0.31(0.43)$

$-0.01(0.36)$

$0.41(0.30)$

Note: Don't know/no response responses are included in the model where available, though not displayed in the table. 
Table A1. Ordered logistic regressions for environmental protection v. income question

Education (University Degree)

2002 2005

Complete Primary or Less

$-0.57(0.34)$

$0.22(0.33)$

Secondary

$-0.46(0.20)^{*}$

$-0.57(0.19)^{* *}$

Nondegree Professional Trade/Technical Tertiary

$-0.17(0.24)$

$-0.46(0.22)^{*}$

Incomplete University

$0.25(0.32)$

$-0.55(0.34)$

Member of Environmental Organisation

$1.55(0.34)^{* *}$

$0.70(0.27)^{* *}$

Left-Right Scale (Centre)

Left

Right

$0.13(0.21)$

$0.90(0.22)^{* *}$

$-0.57(0.20)^{* *}$

$-0.53(0.21)^{*}$

Cut 1

$-3.64(0.29)$

$-4.18(0.35)$

Cut 2

$-2.83(0.26)$

$-2.95(0.27)$

Cut 3

$-1.76(0.23)$

$-1.83(0.24)$

Cut 4

$0.10(0.22)$

$-0.16(0.23)$

Cut 5

$1.30(0.23)$

$1.16(0.24)$

Cut 6

2.34(0.26)

$2.35(0.26)$

Log Likelihood

$-1,001.26$

$-1,004.28$

Number of Respondents

623

623

${ }^{* *} \mathrm{p} \leq 0.01 ;{ }^{*} \mathrm{p} \leq 0.05$; standard errors in parentheses

Note: Don't know/no response responses are included in the model where available, though not displayed in the table. 